\title{
Latino-americanismo e pan-americanismo no Uruguai do entreguerras: entre utopias e distopias
}

\author{
Mateus Fávaro Reis ${ }^{1}$
}

\section{Resumo}

O objetivo do presente artigo consiste em fazer uma reflexão sobre o debate entre os intelectuais uruguaios Emilio Frugoni, José Antuña e Carlos Quijano, em relação ao latino-americanismo e o pan-americanismo, no período entreguerras. Frugoni, Antuña e Quijano contribuíram de forma desigual e por caminhos divergentes para o fortalecimento dos americanismos no Uruguai. Quijano foi um dos principais críticos uruguaios ao pan-americanismo e promoveu a construção de um projeto de união latinoamericana, bem como de crítica anti-imperialista. Frugoni foi o principal artífice do ideário socialista no Uruguai e, apesar de certas divergências iniciais, cruzou sua trajetória com Quijano, ao propor caminhos para a construção da soberania dos Estados latino-americanos. Antuña, por outro lado, foi um confesso adversário de Frugoni, mas também de Quijano, e atuou como um dos mais expressivos defensores do panamericanismo no Uruguai, articulando-o ao hispanismo conservador.

Palavras-chave: Uruguai, latino-americanismo, pan-americanismo

\begin{abstract}
This article intends to reflect on the debate among the Uruguayans intellectuals Emilio Frugoni, José Antuña and Carlos Quijano about Latin-Americanism and PanAmericanism, during the Interwar period. Frugoni, Antuña and Quijano have contributed in uneven and divergent paths to Americanism strengthening in Uruguay. Quijano has been one of the major critical of the Pan-Americanism and has proposed the construction of a Latin America union project, as well as an anti-imperialist critique. Frugoni has been the main architect of socialist ideas in Uruguay and, despite some initial disagreements, his path has crossed with Quijano's, in proposing ways to build the sovereignty of Latin American States. Antuña, on the other hand, has been an avowed opponent to Frugoni, but also to Quijano, and has worked as one of the most significant supporters of the Pan-Americanism in Uruguay, linking it to the conservative Hispanicism.
\end{abstract}

\footnotetext{
${ }^{1}$ Professor Doutor, Universidade Federal de Ouro Preto (UFOP), Brasil. Título da pesquisa em andamento: Identidade e alteridade no Chile: historiografia, ensaios e fotografias sobre os indígenas (1860-1940). E-mail: mateusfav@ @otmail.com

Revista Eletrônica da ANPHLAC, ISSN 1679-1061, n.15, p. 198-224, jul./dez. 2013. http://revista.anphlac.org.br/
} 
Keywords: Uruguay, Latin-Americanism, Pan-Americanism

Artigo recebido em: 30/06/2013

Artigo aprovado em: 23/09/2013

\section{Introdução}

Emilio Frugoni, José Antuña e Carlos Quijano dedicaram parte significativa de suas importantes reflexões à América Latina e aos Estados Unidos - ao pensar o Uruguai numa perspectiva continental -, abarcando os temas do latino-americanismo, hispano-americanismo e pan-americanismo. Foram coetâneos e mantiveram relações de amizade e de crítica em determinados momentos de suas vidas. Além disso, traçaram trajetórias dinâmicas e exerceram grande influência nos meios intelectuais e políticos do país, ao se engajarem na arte da escrita e da ação política de maneira bastante expressiva.

Antuña defendeu o pan-americanismo, em consonância com a posição adotada pelos governos uruguaios, na primeira metade do século XX. Quijano foi um dos principais críticos do projeto pan-americanista no Uruguai e não poupou esforços para combatê-lo por meio de algumas tribunas importantes do país, como os semanários Acción (1932-1939) e Marcha (1939-1974). Frugoni posicionou-se de forma mais hesitante no debate, ainda que em alguns momentos tenha demonstrado certa simpatia pelo discurso latino-americanista. Contudo, criticou ambas as posições, ao vislumbrar outras formas de integração, menos relacionadas a aspectos culturais e geográficos.

O latino-americanismo e o pan-americanismo ocuparam um lugar de destaque na obra dos três intelectuais que, ao abordar os movimentos de integração entre os países americanos, buscaram propor saídas para suas inquietações acerca do futuro do Uruguai, muitas vezes, tingidas pelo tema da viabilidade de um país territorialmente pequeno e modesto em recursos humanos e naturais. Sustentaram que o país platino não poderia pensar em seguir uma trajetória isolada, preocupando-se em desenvolver somente seus potenciais internos. Em suma, a pedra de toque dos três autores consistia em traçar e propor os caminhos de inserção do país no concerto internacional das nações, principalmente no cenário americano.

Vale ressaltar que, apesar de relativamente modesto em recursos naturais e em população, o Uruguai ocupou um lugar estratégico nas relações internacionais na 
América do Sul, entre o Brasil e a Argentina, e foi cenário de um rico debate acerca do futuro dos países latino-americanos. Além disso, assim como no México e no Chile, por seu território, passaram incontáveis exilados políticos e intelectuais, oriundos de diversos países, desde a primeira metade do século XIX até finais da década de 1960, reservando ao Uruguai um espaço bastante significativo para se debater os projetos integracionistas.

Segundo Arturo Ardao (1987), o tema do americanismo recebeu, desde o século XIX, especial destaque na América Latina. Os caminhos para o seu estudo foram traçados por filósofos e historiadores, entre as décadas de 1940 e 50, principalmente na Argentina, México e Uruguai, em obras que buscavam a historicidade do pensamento político de diversos intelectuais do continente.

Ardao (1986, p. 58) também destacou que, a partir de meados do século XIX, o debate sobre o americanismo sofreu mudanças significativas e transpôs o par América/Europa. Novas ideias foram propostas, com especial ênfase para as diferenças que existiam dentro do próprio continente. As noções de América Hispânica, América Ibérica e América Latina delinearam-se, em busca de uma identidade própria em relação à outra América, a anglo-saxônica.

Dentro desse cenário em configuração, receberam especial atenção o latinoamericanismo e o pan-americanismo, ideias que excitaram mentes e, em não menor proporção, os corações, de diversos intelectuais da América Latina, levando-os a estabelecer um frutífero debate em busca das identidades dos povos que conformam essa vasta parte do continente americano.

O período compreendido entre 1889 e 1948 foi crucial para a história do latinoamericanismo e do pan-americanismo. Ainda que não se possa sustentar que o movimento de delineamento da ideia de América Latina tenha ocorrido de fora para dentro, como projeção dos círculos intelectuais europeus em direção à América, segundo Arturo Ardao (1986a), Patricia Funes (1996) e Héctor Bruit (2003), alguns grupos de intelectuais hispano-americanos que viviam na Paris de meados do século XIX atuaram como os motores desse processo. O termo gradualmente passou a ter maior difusão nos círculos intelectuais, incorporando-se a ações oficiais no final da década de 1940, como a criação da Comissão Econômica para a América Latina (CEPAL), com sede em Santiago.

Revista Eletrônica da ANPHLAC, ISSN 1679-1061, n.15, p. 198-224, jul./dez. 2013. http://revista.anphlac.org.br/ 
O seu conteúdo básico consistia numa aproximação e desejável integração cultural, política e econômica dos países latino-americanos, em um período em que muitos intelectuais se engajaram em torno a revistas, associações culturais, clubes de debate e de estudos, na virada do século XIX para o XX, como demonstraram Susana Zanetti (1994) e Beatriz Colombi (2004). Tais autoras assinalaram que os intelectuais latino-americanos, particularmente os hispano-americanos, aproximaram-se devido às viagens que realizaram, ao exílio, à diplomacia, à participação conjunta em revistas e periódicos, além da troca de correspondências, o que levou ao fortalecimento da ideia de pertencimento a um espaço cultural comum.

Por outro lado, o pan-americanismo representava a busca pela articulação econômica, política e cultural entre todos os países americanos, particularmente sob a liderança dos Estados Unidos. O projeto ganhou seus contornos iniciais com a realização da Conferência Internacional Americana, em Washington, entre outubro de 1889 e abril de 1890 , e, durante toda a primeira metade do século XX, ocupou a agenda política e intelectual dos países americanos ${ }^{2}$. O termo derivou-se de Pan-América e foi cunhado pela imprensa norte-americana, em meados de junho de 1889 , referindo-se ao congresso que estava programado para outubro do mesmo ano, ganhando grande difusão no léxico internacional (ARDAO, 1986b, p. 157-158).

Com o passar dos anos, os olhares dos intelectuais se aguçaram e, "numa relação especular mutuamente fascinada, os Estados Unidos e a América Latina construíram uma série de saberes sobre si e sobre o outro, sem os quais resultaria incompreensível a emergência do anti-imperialismo latino-americano" (TERÁN, 1981, p. 3).

Nesse sentido, concordamos com Maria Helena Capelato (1994, p. 85), ao asseverar que a América Latina é uma "unidade diversificada", que esteve, ao longo dos séculos XIX e XX, permeada por um dilema importante entre a unidade e o particularismo, acentuado em períodos de crise. A ideia de integração esteve presente em diversos momentos de sua história com contornos divergentes, mas com a base comum de constituir uma barreira ao domínio dos Estados Unidos sobre a América Latina. Esse cenário conflituoso estimulou os intelectuais a se enveredar por caminhos que pudessem desvendar os elementos de uma identidade "americana".

A despeito de pertencer ao tronco hispano-americano, o Uruguai oscilou, durante a primeira metade do século XX, entre ser e não ser América Latina, ressaltando mais as

\footnotetext{
${ }^{2}$ Sobre as Conferências Pan-Americanas, consultar: DULCI (2008).

Revista Eletrônica da ANPHLAC, ISSN 1679-1061, n.15, p. 198-224, jul./dez. 2013. http://revista.anphlac.org.br/
} 
suas diferenças do que afirmando as semelhanças com os demais países da região (CAETANO, 1993). Em grande medida, isso se deveu à grande transformação pela qual passou o país platino, entre 1870 e 1930, ao receber um afluxo muito expressivo de imigrantes, majoritariamente de europeus meridionais (ZUBILLAGA, 1999). Foram realizadas mudanças significativas na sociedade uruguaia, que atingiram seu ápice com a entrada do século XX, após a ascensão ao poder estatal de um grupo político republicano reformista, oriundo do Partido Colorado, denominado de batllista, capitaneado por José Batlle y Ordóñez. Batlle y Ordóñez foi presidente do Uruguai em dois mandatos não consecutivos: 1903-1907 e 1911-1915, durante os quais logrou capitanear significativas transformações no país platino ${ }^{3}$.

Frugoni, Antuña e Quijano cresceram nesse período de profundas mudanças do Uruguai, transformando-se nos principais debatedores sobre o lugar cultural e político do país no concerto americano. Assim, dialogaram habitualmente com as interpretações elaboradas por José Enrique Rodó ${ }^{4}$ sobre as diferenças entre os povos latino ou hispanoamericanos e os norte-americanos e defenderam distintos projetos de integração no interior do continente americano.

\section{Itinerários intelectuais}

Os três autores foram selecionados, porque dedicaram parte significativa de suas importantes reflexões à América Latina e aos Estados Unidos - ao pensar o Uruguai numa perspectiva continental -, abarcando os temas do latino-americanismo, hispanoamericanismo e do pan-americanismo; foram coetâneos e mantiveram relações de amizade e de crítica em determinados momentos de suas vidas. Além disso, traçaram trajetórias dinâmicas e exerceram grande influência nos meios intelectuais e políticos do

\footnotetext{
${ }^{3}$ Os batllistas, que tinham um forte respaldo das camadas médias urbanas e dos imigrantes, de forma significativa, na educação pública, promulgaram leis trabalhistas como a jornada laboral de oito horas semanais, o direito de realizar greve e outras garantias para os trabalhadores; legalizaram o divórcio por vontade de qualquer um dos cônjuges; empenharam-se em uma luta pela secularização dos hospitais, dos cemitérios e do calendário; dentre outras importantes reformas (BARRÁN; NAHUM, 1979-1987; CAETANO, 2011).

${ }^{4}$ De maneira bastante sintética, Rodó adaptou os personagens da peça A Tempestade (1611-612), de William Shakespeare, para tramar a contraposição de seus personagens principais, Calibán e Ariel, em face de Próspero. O primeiro, anagrama de Canibal, se caracterizava pelo utilitarismo interessado, vulgarização da cultura, individualismo medíocre e pela democracia baseada no número. Para Rodó, essas características anulavam qualquer noção de qualidade em Calibán. Assim, representava a preocupação absoluta com o triunfo material, a despeito de qualquer densidade histórica. Ariel, em contrapartida, representava a tradição humanista, herdeira, para o autor uruguaio, da cultura greco-latina, com seu idealismo e espiritualismo que convergiam para a ação não utilitarista dos povos que haviam sido colonizados pelos espanhóis e portugueses. O livro intitulado Ariel obteve ampla repercussão entre os intelectuais latino-americanos.
}

Revista Eletrônica da ANPHLAC, ISSN 1679-1061, n.15, p. 198-224, jul./dez. 2013. http://revista.anphlac.org.br/ 
país, ao se engajarem na arte da escrita e da ação política de maneira bastante expressiva.

A existência de visões divergentes entre os três autores, no debate sobre os projetos de integração continental, foi um dos critérios mais relevantes para a sua seleção: José Antuña, por defender frequente e ardorosamente o pan-americanismo; Quijano, por fincar raízes no campo oposto; Frugoni, por se posicionar de forma mais hesitante no debate, ainda que, em alguns momentos, tenha demonstrado certa simpatia pelo movimento latino-americanista, criticando ambas as posições, ao vislumbrar outras formas de integração, menos relacionadas a aspectos culturais e geográficos.

Portanto, os posicionamentos dos três intelectuais foram diferentes ao longo de suas trajetórias, que se entrecruzaram devido a debates parlamentares e críticas recíprocas. A despeito disso, os caminhos de Frugoni e Quijano convergiram a partir de meados da década de 1930, durante o governo ditatorial de Terra, ao passo que aprofundaram suas dissonâncias em relação a Antuña.

Principal arquiteto do Partido Socialista do Uruguai, fundado em 1910, Emilio Frugoni destacou-se por suas atividades intelectuais e políticas, muito além da esfera intrapartidária. Frugoni deu os primeiros passos na vida pública uruguaia entre os círculos do Partido Colorado, mas gradativamente ladrilhou os caminhos do que ele denominava uma política de ideias contra o tradicionalismo e elegeu-se deputado por várias vezes. Na esfera cultural e intelectual, Frugoni foi poeta, crítico de teatro, professor de literatura no ensino secundário e de direito no universitário, além de diretor de jornais e revistas, quase sempre vinculados ao Partido Socialista. Exilado na Argentina durante o início do governo ditatorial de Gabriel Terra ${ }^{5}$, em 1933 e 1934, e representante diplomático do Uruguai na União Soviética, de 1944 a 1946, Frugoni buscou interpretar e adaptar o socialismo à realidade uruguaia e latino-americana, criticando as prédicas e táticas sustentadas por seus intelectuais e partidos comunistas.

Frugoni viu a política como missão do intelectual e adotou uma postura de contínuo engajamento de sua obra na vida política. Em meio à sua agitada primeira década (anos 1910) de desempenho na vida parlamentar do Uruguai, começou a se desenhar o Frugoni latino-americanista.

\footnotetext{
${ }^{5}$ Gabriel Terra foi eleito presidente do Uruguai pelo Partido Colorado, em 1930. Durante os dois primeiros anos de seu primeiro mandato, 1931 e 1932, articulou-se a grupos sociais e políticos da sociedade uruguaia, que apontavam caminhos mais centralizadores e autoritários para responder aos desafios colocados pela depressão econômica. Após o golpe, em 1933, iniciou seu segundo mandato, exercido até 1938 (JACOB, 1983; CAETANO; JACOB, 1989).

Revista Eletrônica da ANPHLAC, ISSN 1679-1061, n.15, p. 198-224, jul./dez. 2013. http://revista.anphlac.org.br/
} 
Nos últimos anos desta década, Frugoni debutou no debate sobre as relações entre a América Latina e os Estados Unidos. Suas atenções foram estimuladas tanto pela viagem realizada aos Estados Unidos, em 1915, acompanhado de sua mãe e de sua irmã, quanto pela morte de Rodó, em 1917.

Durante os anos 1920, em um ambiente intelectual latino-americano que dissertava habitualmente sobre a situação do México pós-revolucionário, Frugoni (1928) proferiu duas conferências sobre o país setentrional na Universidade da República. Interpretou positivamente a Revolução Mexicana e avaliou com simpatia a disputa entre o governo e a Igreja Católica pelas terras no país, além de ver os Estados Unidos como uma ameaça real à soberania do México.

Nesse período, já preparava a publicação de La sensibilidad americana (1929), uma recopilação de escritos publicados durante a década de 1920, sobre aspectos das especificidades culturais latino-americanas, o papel da intelectualidade e da arte na região. Também cabe ressaltar que essa obra de Frugoni foi publicada em um período em que o autor demonstrava uma clara inclinação para a defesa de que as ideias na América, ainda que oriundas de outras coordenadas geográficas, encontravam um terreno fértil, aclimatando-se e americanizando-se de forma fecunda e original.

A trajetória frugoniana se desenrolou mediante o engajamento pela defesa da democracia, liberdade, ética e justiça social. Em tempos de ascensão de ideias e regimes autoritários na América Latina, na Europa e em outras partes do mundo, Frugoni escreveu copiosamente a favor da democracia política, econômica e social. Explicitou uma visão muito crítica sobre a União Soviética, destacando a falta de liberdade política e individual, além da opressão dos operários do país, e reafirmou sua crença na construção de um socialismo democrático.

José Antuña traçou percursos bem distintos aos de Frugoni. Desde sua juventude, aproximou-se dos setores conservadores do Partido Colorado e desaprovou o projeto de secularização promovido pelos batllistas. Poeta, jornalista, ensaísta, jurista, deputado e senador, Antuña sublinhava que o americanismo representava o seu tema preferido. Com uma atuação extremamente importante em prol do pan-americanismo, transformou-se em um dos líderes da política cultural terrista e presidente da VII Conferência Pan-Americana, realizada em Montevidéu, em dezembro de 1933, Antuña recebeu muitas críticas dos grupos de oposição àquela ditadura. Assim, edificou sua carreira política entre as correntes conservadoras e elitistas, que promoveram o "freio"

Revista Eletrônica da ANPHLAC, ISSN 1679-1061, n.15, p. 198-224, jul./dez. 2013.

http://revista.anphlac.org.br/ 
às reformas batllistas, e acolheu favoravelmente o hispanismo católico que se transformou na argamassa de seus projetos para o Uruguai e para a América Hispânica.

A sua estreita relação com o terrismo - ao passo que Frugoni fora desterrado para a Argentina e Quijano perseguido -, abriu-lhe as portas de diversas atividades desenvolvidas no âmbito das relações internacionais. Além do exercício de um cargo de destaque durante a VII Conferência Pan-Americana, realizada em Montevidéu, em 1933, Antuña encarregou-se de diversas missões intelectuais, entre 1936 e 1938, na França, Argentina, Chile e Brasil, aonde fez diversas conferências em institutos oficiais e acadêmicos.

Frugoni foi o principal crítico do posicionamento de Antuña, quando o classificou como um "molusco desatento" e utilizou um vocabulário agressivo para atacar sua atuação como ideólogo do terrismo, ao denominar suas formulações de "defecações [sic] doutrinárias" (FRUGONI, s/d, p. 41).

Simultaneamente ao destaque obtido na cena política uruguaia, quando se elegeu senador, Antuña canalizou seus esforços no sentido da difusão de seu pensamento, ao publicar três obras, que foram premiadas por comissões culturais vinculadas ao governo de Terra: El nuevo acento (1935), El inquieto horizonte (1937) e Perspectivas de América (1938). À exceção da segunda, na qual analisava principalmente a crescente e preocupante tensão europeia, Antuña privilegiou o tema do "americanismo", ao expor sua visão a respeito da realidade cultural e política da América Latina e conjugar a defesa, nem sempre comum, do hispanismo com o projeto pan-americanista.

Por outro lato, figura de maior projeção intelectual na arena nacional e latinoamericana entre os três, Carlos Quijano defendeu que era necessário fazer política por meio da escrita. Capitaneou a fundação de importantes periódicos no Uruguai, como o diário El nacional, bem como os semanários Acción (1932-1939) e Marcha (19391974), que entrelaçaram os horizontes uruguaios ao projeto latino-americanista em contraposição ao pan-americanismo. Escreveu a favor do México, dos países centroamericanos e caribenhos contra as incursões estadunidenses, sem deixar de criticar, a seu ver, a incipiente transformação fundiária mexicana após 1917 e vários governos conservadores e ditatoriais daquelas regiões.

Quijano consolidou seu discurso latino-americanista, articulado ao antiimperialismo, ao participar do Congresso Anti-imperialista celebrado em Bruxelas, em 1927, com a participação de intelectuais comprometidos com as lutas políticas do 
período, como, entre outros, Henri Barbusse, Romain Rolland, Albert Einstein e José Vasconcelos (CAETANO; RILLA, 1986, p. 186-187).

Em 1928, publicou Nicaragua, ensayo sobre el imperialismo de los Estados Unidos, às vésperas de sua viagem a Havana, aonde participou de manifestações que criticavam a VI Conferência Pan-Americana.

A partir dos anos 1930, Quijano fincou raízes no jornalismo e na crítica, para repensar todo o quadro político, econômico, social e cultural do Uruguai, propondo novas direções para a edificação de uma nação que, a seu ver, possuía alicerces frágeis e excessivamente condicionados pelo concerto internacional, que havia mostrado a fragilidade de sua proclamada democracia e institucionalidade em 1933.

\section{Latino-americanismo e pan-americanismo no entreguerras}

Desde o falecimento de Rodó até o final da Segunda Guerra Mundial, Frugoni, Antuña e Quijano dedicaram especial atenção para as relações entre o Uruguai, os demais países latino-americanos e os Estados Unidos e teceram divergentes interpretações acerca do latino-americanismo e do pan-americanismo.

Durante quase sessenta anos (1889-1948), o pan-americanismo buscou impulsionar a integração das Américas em torno de objetivos comuns, por meio de distintos canais de instrumentalização política e institucional, mas também econômica e, em alguns casos, cultural. A América do Sul organizou a maior parte das conferências realizadas, o que sinalizava os interesses dos norte-americanos em aliar-se aos países daquela região do globo.

No Uruguai, ainda que desde a década de 1870 os Estados Unidos mantivessem um representante em seu território, somente em 1941 a sua legação diplomática foi elevada à categoria de embaixada, em um período em que o país se tornou uma peça estratégica no Atlântico Sul, durante a Segunda Guerra Mundial, e da posição de neutralidade da Argentina.

Não cabe dúvida de que as reuniões, apesar das demonstrações de apoio e solidariedade, foram marcadas por uma constante hesitação das delegações latinoamericanas, a respeito das propostas norte-americanas, o que dificultava lançar as bases para a instrumentalização política e institucional dos projetos discutidos em seu interior. Durante a realização da IV Conferência em Buenos Aires, em 1910, foi criada a União Pan-Americana, com sede na capital norte-americana, a qual almejava estabelecer um 
local que representasse aquele movimento e que pudesse se constituir em um centro de encontro e de estudos dos representantes dos distintos Estados-membros.

Durante a V Conferência, realizada em Santiago do Chile, em 1923, a presidência da União Pan-Americana passou a ser escolhida por meio de eleições entre as delegações. Entretanto, Quijano (1932) denunciou que, mesmo assim, os Estados Unidos continuaram a presidi-la, pois o secretário desse país sempre fora eleito pelos demais membros.

No que toca o campo da história, duas iniciativas receberam especial atenção a partir das conferências realizadas em Havana e Montevidéu; em primeiro lugar, com a fundação do Instituto Pan-Americano de Geografia e História (IPGH), na Cidade do México, em 1929, um ano após a sua aprovação pelos participantes da VI Conferência Pan-Americana em Havana. Na capital uruguaia, foi realizada, durante a VII Conferência Pan-Americana, a Convenção Sobre o Ensino de História, cuja proposta consistia em promover a revisão dos textos veiculados pelos livros didáticos de história, com o intuito de depurá-los de qualquer conteúdo que sugerisse dissensões entre as nações americanas (GONZÁLEZ; RAMÍREZ, 2007).

Todas essas iniciativas, mencionadas de forma bastante resumida, estimularam os políticos e intelectuais latino-americanos a olhar com maior zelo para os perigos e as vantagens em se aproximar dos vizinhos norte-americanos, ao mesmo tempo em que propiciaram uma maior articulação dos grupos contrários ao pan-americanismo em torno de projetos alternativos e fundamentalmente animados por intelectuais, como, por exemplo, a Alianza Popular Revolucionaria Americana (APRA), capitaneada pelo peruano Víctor Raúl Haya de la Torre, a partir de 1924; a Unión Latinoamericana, organizada por José Ingenieros em Buenos Aires, em 1925; e a Liga Antiimperialista de las Américas (LADLA), dirigida pelos mexicanos Úrsulo Galván e Diego Rivera, também em 1925 (FUNES, 2005, p. 226-229).

Frugoni, Antuña e Quijano relacionaram-se de maneiras divergentes com tais grupos e foram os autores uruguaios mais assíduos nesse debate, durante as décadas de 1920,30 e 40.

Frugoni, desde a publicação na revista argentina Nosotros, em 1918, do relato da viagem que havia realizado aos Estados Unidos, três anos antes, intitulado En la otra América, passou a conceder uma significativa atenção àquele país e, embora não tenha citado Ariel, não conseguiu desvincular-se da trama tecida na obra de Rodó.

Revista Eletrônica da ANPHLAC, ISSN 1679-1061, n.15, p. 198-224, jul./dez. 2013. http://revista.anphlac.org.br/ 
Se de um lado, assinalou os diversos aspectos positivos dos Estados Unidos, designados como uma "nação de prodígios modernos", com uma população progressista, ativa, estudiosa, concisa, penetrante e também vaidosa, por outro, concluiu, pelo veio utilitário que adentrava todas as atividades dos norte-americanos, inclusive dos homens de letras: "Esta ideia da nobre condição do lucro é tão profunda que conseguiu a conciliação perfeita do que parecia ser irreconciliável. As mais elevadas ocupações do espírito e da inteligência aparecem irmanadas com o lucro, sem que esse as descore" (FRUGONI, 1918, p. 343).

A visão de Frugoni sobre os Estados Unidos realçava seus contrastes, que, a seu ver, pouco assimilava os exemplos externos, à exceção das esferas científicas e artísticas que mantinham suas portas constantemente abertas ao exterior. $\mathrm{O}$ autor socialista criticou a manutenção da pena de morte como uma ferramenta de punição jurídica. Assim, chamou atenção para a "barbárie" norte-americana da pena de morte, envolta por um nefando clima de festa, e citou os convites para as execuções por meio da cadeira elétrica em Nova Iorque, bem como os pic nics que conglomeravam os sulistas após um enforcamento. Dessa forma, não deixava de dialogar com uma espécie de antinorte-americanismo que se difundia na América Latina.

Posteriormente, Frugoni (1941, p. 112-113), interessado em propor os caminhos do socialismo latino-americano, ao confrontar as suas experiências anglo-saxônicas, destacou, em mais de uma oportunidade, o exíguo espaço dedicado pelos trabalhadores estadunidenses à discussão de ideias e ideologias que fossem além das reivindicações por melhorias salariais ou sindicais, devido, a seu ver, à absorvente preocupação mercantilista, ao passo que o trabalhismo britânico emergia como uma significativa fonte de inspiração.

Cabe assinalar que em Génesis, esencia y fundamentos del socialismo (1947), Frugoni confirmou sua visão sobre os trabalhadores norte-americanos, segundo ele, pouco articulados ao Partido Trabalhador Socialista (Social Labour Party), e que eram adversários dos anarcocomunistas e da própria Federação Americana do Trabalho (American Federation of Labour). Para Frugoni, a ideia de "reforma social pela via econômica" continuava a dar as coordenadas para os trabalhadores dos Estados Unidos. A visão tramada não caminhava em grande parte, portanto, pelo viés do antiimperialismo, mas bebia em fontes que salientavam o caráter utilitarista e individualista do povo norte-americano. Em suma, não representavam necessariamente um modelo a

Revista Eletrônica da ANPHLAC, ISSN 1679-1061, n.15, p. 198-224, jul./dez. 2013. http://revista.anphlac.org.br/ 
ser seguido para a construção do socialismo no Uruguai. Entretanto, Frugoni nem sempre apoiou a ideia de um projeto de integração que se restringisse à América Latina e defendeu a união dos setores trabalhadores de todas as Américas, a favor da construção do socialismo democrático.

Antuña e Quijano, por sua vez, não chegaram a publicar textos mais penetrantes sobre a sociedade norte-americana e circunscreveram suas interpretações antagônicas sobre as relações entre a América Latina e os Estados Unidos.

Desde 1917, Antuña expressou o seu apoio ao pan-americanismo e assinalou que o Uruguai se tornou uma peça fundamental para os norte-americanos, nos mares do Atlântico Sul, a partir da entrada dos Estados Unidos na Primeira Guerra Mundial. Para Antuña, todos os países americanos deveriam apoiar os Estados Unidos e nutrir o panamericanismo, transformando-o em um "Zollverein Americano" que, a seu ver, deveria ancorar-se na Doutrina Monroe e no exemplo de George Washington. Antuña destacou, em diversas passagens, que as diretrizes da política externa norte-americana não representavam ambições de dominação, mas de luta pelo pacifismo, pela liberdade e encarnavam "a negação rotunda do cesarismo e autocracia” (ANTUÑA, 1924, p. 91).

O intelectual e deputado colorado contestou as críticas lançadas às investidas dos Estados Unidos sobre o México e argumentou que, quando as tropas norte-americanas adentraram o território mexicano, o país "se encontrava anarquizado e sua sangrenta convulsão dava origem aos repetidos incidentes fronteiriços”. Além disso, Antuña (1924) sustentou que o próprio governo mexicano consentira inicialmente a ação dos norte-americanos, dentro de um delimitado raio, em torno dos limites de ambos os países (ANTUÑA, 1924, p. 92).

Finalmente, Antuña (1924) criticou as representações iconográficas dos livros do argentino Manuel Ugarte (1923) sobre os Estados Unidos, que satirizavam a águia exposta nos brasões das forças militares norte-americanas, e aprovou a sua expansão sobre a América Latina:

Em que se funda, portanto, a propaganda antipan-americanista que se esforça por nos apresentar a grande democracia do norte, tal como aparece na capa dos livros de Ugarte, como uma águia obsessiva, de garras sangrentas, que desde o mastro da insígnia estrelada está sempre pronta para precipitar sua voracidade furiosa sobre a América Latina?

Realmente constitui uma força conquistadora, mas sejam bem-vindas essas conquistas, uma vez que elas não arrancam nem do baixo espírito expansionista, nem do afã imoderado da velha dominação material. São estas as conquistas da paz e do trabalho, do progresso e da ordem, que em forma

Revista Eletrônica da ANPHLAC, ISSN 1679-1061, n.15, p. 198-224, jul./dez. 2013. http://revista.anphlac.org.br/ 
da emulação e do exemplo, chegaram a invadir os países da América espanhola subsumidos na dissolução e no opróbrio. Dessa maneira, explicase que em alguns povos da América Central e no próprio México possa ser surpreendido um determinado sentimento anexionista, nem muito vago nem demasiado obscuro, a ponto de que como anota um autor argentino, assim como ocorria com Cuba durante a dominação espanhola, muitos dos homens mais importantes daqueles países adotaram a cidadania americana [sic] para se ver livres dos atropelos das autoridades locais. (p. 94-95)

Antuña não deixava dúvidas a respeito de sua visão favorável aos Estados Unidos e extremamente pejorativa sobre os países da América hispânica. Os "prósperos" norte-americanos eram vistos como exemplos, e o intelectual não via qualquer problema em que suas "forças conquistadoras" se expandissem por todo o continente. Pelo contrário, eram bem-vindas, em um continente que se caracterizava pela "desordem". Sua visão pessimista não estava desarticulada das lutas que ocorriam internamente no Uruguai, que, após o governo conservador de Feliciano Vieira, entre 1915 e 1919, voltava para as mãos dos batllistas, liderados por Baltasar Brum até 1923.

Em 1926, o argentino Arturo Capdevilla publicou entre os membros da Unión Latinoamericana uma obra de crítica aos Estados Unidos e a alguns povos latinoamericanos, desde "Buenos Aires, cidade forte". A mensagem de Capdevilla (1926) era deliberadamente de denúncia às ações norte-americanas na América Central, no México e no Caribe, mas, por outro lado, de advertência à necessidade de tais povos se fazerem respeitar, consolidando as bases de verdadeiros Estados-nacionais.

No ano seguinte, Antuña publicou um artigo sobre o livro de Capdevilla tanto na revista francesa L'Amérique Latine, em janeiro, quanto na argentina Nosotros, em fevereiro, cuja apropriação das ideias expostas pelo autor argentino se mostrou bastante seletiva. Antuña invertia a ênfase da obra de Capdevilla e até mesmo a imagem de Buenos Aires como cidade forte, já não como uma fortaleza de resistência, mas como cidade dotada de vigor e virtuosa, "porque soube criar-se com ordem, ciência e energia" (ANTUÑA, 1927, p. 82).

O intelectual colorado queria desvendar "a verdade da América", em alusão à América Hispânica. Para tanto, utilizou um léxico inquestionavelmente patológico e assinalou que, ao contrário dos argentinos, os demais povos do continente careciam de vontade para edificar verdadeiras nações. Antuña (1927) assentiu parcialmente com Capdevilla acerca da existência do imperialismo norte-americano. Contudo, sustentou novamente que, muitas vezes, os Estados Unidos intervieram em seus vizinhos próximos ou distantes porque haviam sido convocados (p. 82).

Revista Eletrônica da ANPHLAC, ISSN 1679-1061, n.15, p. 198-224, jul./dez. 2013. http://revista.anphlac.org.br/ 
O argumento de Antuña (1927) se radicava sobre a "debilidade", "instabilidade" e "desorganização" dos países latino-americanos, os quais não se faziam respeitar pelos norte-americanos:

\begin{abstract}
Pouco respeitosos foram para com a América Latina os Estados Unidos, afirma o autor de América. Entretanto, quão certo é também que "não se respeita senão o respeitável", agrega, ao mesmo tempo em que recorda que, assim como o ciclope legendário devorava mais facilmente os carneiros do que os homens, este outro ciclope primeiro comerá rebanhos vagabundos do que verdadeiros povos. (p. 86)
\end{abstract}

Ainda que Antuña geralmente não articulasse deliberadamente as conformações étnicas latino-americanas com a suposta anarquia de suas nações, uma vez que buscava inverter as visões negativas também a respeito da "raça" espanhola, suas palavras muito pouco alentadoras certamente não poderiam ser bem recepcionadas entre os expressivos grupos intelectuais dos anos 1920 aos 1940, que empreendiam uma verdadeira revisão crítica dessas interpretações tanto nas Américas quanto na Europa. Além disso, suas palavras não deixavam de ser muito injuriosas, ao falar em termos de "rebanhos vagabundos".

Quijano, ao contrário de Antuña, desde finais da década de 1910 expressava seus reproches à política externa norte-americana para a América Latina. Durante a sua estadia na Europa, de 1924 a 1928, ao travar estreitos contatos com outros jovens estudantes hispano-americanos, dentre outros importantes intelectuais, Quijano cultivou um discurso anti-imperialista, que gradualmente ampliava o seu espectro de recepção, tanto entre os círculos intelectuais latino-americanos e asiáticos, quanto europeus.

Embora o Uruguai da juventude de Quijano se mantivesse um pouco distante das investidas políticas, econômicas e culturais dos Estados Unidos, ele não deixou de apontar que os principais desafios para os países latino-americanos viriam de suas relações desencontradas ou dialógicas com aquela poderosa nação, que, desde a primeira metade do século XIX, direcionava permanentemente suas atenções sobre os seus vizinhos do sul, como ressaltou Mary Junqueira (2007).

Cabe lembrar que o olhar anti-imperialista de Quijano foi construído em articulação ao seu latino-americanismo, visto como um projeto que demandava esforço e criatividade para se consolidar entre os meios intelectuais e políticos da América Latina (ARDAO, 2003). Quijano sabia que existiam muitas dificuldades para conciliar 
os interesses, nem sempre coincidentes de todos os países latino-americanos, além de ir contra a corrente mais comum, que via o Uruguai como um país excepcional.

Entretanto, podem-se observar, em alguns de seus textos, considerações paralelas às tramadas por Capdevilla (1926) e Antuña (1927) acerca da responsabilidade dos países latino-americanos diante do crescente assédio dos Estados Unidos sobre a América Latina.

Quijano criticou a política externa do partido colorado, com os batllistas ou outras agrupações à frente do governo, que defendia o estreitamento de laços com os norte-americanos, em parte para evitar conflitos contra os grandes e poderosos vizinhos, que nem sempre eram vistos com bons olhos em termos de política internacional.

Os riscos de cair sob o comando da Argentina ou do Brasil ainda não estavam completamente esquecidos, pois os dois países interferiram nos assuntos internos do Uruguai, até finais do século XIX, mantendo as disputas de limites por um longo tempo, mesmo com o fim dos litígios com o Brasil, no início do século XX.

Durante os anos 1940, ao concluir uma interessante análise sobre a política externa uruguaia, Quijano (1944) voltou a tocar nesse tópico, com uma visão mais matizada, apesar de não refutar uma parcela de responsabilidade "individual" e coletiva, presente na construção de relações respeitosas entre os latino-americanos e os anglosaxões:

Pessoalmente, em nossas relações com muito cordiais e finos amigos ingleses e ianques, comprovamos que o anglo-saxão respeita a quem se faz respeitar. Não lhe concedemos a isso maior importância, como se compreenderá, porque sabemos que o jogo internacional é um jogo de forças. Se as forças têm que cumprir seus fins, as barreiras morais ou psicológicas pouco contam. Contudo, seria tolo desprezar o que nos é útil e o que, além disso, é sempre demonstrativo de dignidade. (p. 5)

Também ao longo dos anos 1920 e 30, Frugoni apoiou o México, criticou o panamericanismo e as ações norte-americanas em seu entorno mais próximo, sustentou que a política dos Estados Unidos era conduzida por Wall Street e constantemente denominou a sua democracia de plutocracia, isto é, uma falsa democracia que se orientava pelos interesses econômicos dos grupos mais poderosos.

Sismógrafo das inquietações dos estudantes universitários uruguaios, a revista universitária Ariel, fundada com a participação de Quijano em 1917, mostrava-se bastante receptiva às interpretações de Quijano e Frugoni, em sintonia com os papéis desempenhados pelos dois intelectuais como docentes na Faculdade de Direito e

Revista Eletrônica da ANPHLAC, ISSN 1679-1061, n.15, p. 198-224, jul./dez. 2013. http://revista.anphlac.org.br/ 
Ciências Sociais, quando, várias vezes, foram eleitos como seus representantes nos conselhos universitários. Entretanto, em 1930, a revista Ariel condenou o voto favorável de Quijano pela contratação de um empréstimo com bancos norte-americanos ou ingleses, tema sobre o qual se desentendera com Frugoni no parlamento.

Frugoni desaprovou completamente a assinatura do contrato, ao passo que Quijano não via outra saída para o Uruguai, que carecia de financiamento interno e necessitava modernizar sua infraestrutura viária e hidrográfica. Entretanto, Quijano reprovou veementemente a contratação do empréstimo com bancos e agências financiadoras oriundas dos Estados Unidos, optando pelo pagamento de juros mais elevados aos britânicos (DIARIO DE SESIONES DE LA CÁMARA DE REPRESENTANTES, 1931, p. 464).

A revista Ariel posicionou-se a favor de Frugoni e publicou o texto escrito pelo parlamentar socialista acerca dos desafios enfrentados pelos trabalhistas ingleses na Índia, ao passo que censurou duplamente as ações de Quijano, tanto em seu desempenho diante dos estudantes universitários, quanto no parlamento, classificandoas de "atitudes envoltas nas nebulosidades das falsas posições":

Essa é também sua posição frente ao seu eleitorado, que o votou de acordo com as ideias de esquerda que expunha em sua plataforma eleitoral, ao qual se burla, votando em empréstimos, que contêm cláusulas que abrem as portas da economia do país aos avanços vorazes do capitalismo estrangeiro. (FRUGONI, 1930, p. 4-6)

Com tal reprovação, os estudantes demonstravam que acompanhavam de perto tanto o discurso de Quijano, quanto as suas posições parlamentares, e que não acatavam a meticulosa e fundamentada justificativa erigida por Quijano para convencer Frugoni a respeito da necessidade daquele empréstimo.

O tema do pan-americanismo também esteve presente na Liga das Nações e foi alvo de intensas discrepâncias, fundamentalmente em relação ao famoso Artigo 21, que reconhecia a compatibilidade do seu pacto com a Doutrina Monroe (1823) e, como censurou Quijano (1933a), legitimava-a como "acordo regional", admitindo implicitamente a tutela dos Estados Unidos nas Américas.

Diante disso, Quijano (1933a) propunha a sua derrogação, criticava a aceitação dos representantes uruguaios ao texto, denominando-os de "iancófilos", e assinalava que outros países, tais como a Argentina e o México, haviam sustentado posições mais sensatas e favoráveis à América Latina.

Revista Eletrônica da ANPHLAC, ISSN 1679-1061, n.15, p. 198-224, jul./dez. 2013.

http://revista.anphlac.org.br/ 
Antuña (1929), por outro lado, ao participar da delegação uruguaia na Liga das Nações, em setembro de 1929, não parece ter feito amplas censuras ao Artigo 21 e lamentou a adesão tardia dos Estados Unidos ao Estatuto da Corte Permanente de Justiça Internacional de Haia, além de preconizar a aproximação da Liga das Nações com a União Pan-Americana, o que, a seu ver, seria fecundo para a América Latina.

Quijano criticou, em 1932, a plataforma da diplomacia e da política externa uruguaia, tanto na Liga das Nações, quanto na União Pan-Americana, em um contexto de batalha contra os representantes dos setores conservadores, que dirigiam o país, nucleados pelo governo colorado de Gabriel Terra. Em meados da década seguinte, quando as negociações para a criação da Organização das Nações Unidas caminhavam a passos longos, Quijano novamente criticou a possibilidade da aprovação de um "estatuto independente" interamericano em seu seio, além de reprovar o apoio panamericanista do Brasil, visto como "o soldado dos Estados Unidos na América do Sul" (QUIJANO, 1945, p. 4-5).

É interessante notar que, no mesmo editorial, Quijano buscou inscrever a atuação de Antuña no bloco de oposição à redação do Artigo 21, ainda que uma leitura minuciosa dos discursos proferidos pelo representante colorado na Liga das Nações, ou de outros textos coetâneos em que abordou a Doutrina Monroe, não nos permita sustentar completamente a afirmação de Quijano. Aliás, vale sublinhar que Antuña (1938) argumentou que a interpretação exagerada do artigo 21 havia gerado uma infecunda reserva e renúncia da América Latina à Liga das Nações (p. 131).

Possivelmente, Quijano não quis ser injusto com Antuña, apesar de haver discordado de suas posições a respeito da política nacional, internacional e também de seus fundamentos teóricos, pois Antuña discursara em alguns momentos sobre a edificação de um pan-americanismo, ancorado na "igualdade" de relações entre os países das Américas, a aproximação cultural e, em casos de conflitos, a arbitragem ampla, tradicional reivindicação uruguaia na União Pan-Americana e na Liga das Nações.

Ao longo dos anos 1930, Quijano utilizou a redação de Acción para ministrar cursos e conferências, aos quais eram convidados tanto os seus funcionários e colaboradores, quanto o público leitor em geral, uma vez que, desde maio de 1932, passaram a ser anunciados em destaque na capa do semanário. Naquele ano, Quijano privilegiou o tópico do imperialismo econômico e político, ao dissertar sobre as disputas

Revista Eletrônica da ANPHLAC, ISSN 1679-1061, n.15, p. 198-224, jul./dez. 2013. http://revista.anphlac.org.br/ 
europeias pela conquista de territórios, particularmente sobre o imperialismo inglês e francês, bem como a ascensão dos Estados Unidos.

Cabe ressaltar que muito provavelmente os diversos textos sobre a América Latina, o latino-americanismo e o pan-americanismo, publicados por Arturo Ardao posteriormente, além de parte dos conteúdos que ministrou como professor de história das ideias na Universidad de la República, desde os anos 1950 até 1973, fundamentaram-se inicialmente nos textos pronunciados ou escritos por Quijano, em uma conjuntura de ascensão dos movimentos e das ideias fascistas em diversos meridianos.

À medida que se aproximava a Conferência do Uruguai, em 1933, Acción acentuava gradativamente suas críticas ao pan-americanismo e preconizava que seria melhor para a América Latina que os seus trabalhos fossem cessados, porque os seis encontros realizados até então não haviam dado frutos significativos. Para Quijano (1933b), os Estados Unidos sempre se esquivaram da temática relacionada às intervenções. Criticava as relações econômicas entre as nações americanas regidas pelo protecionismo e a União Pan-Americana que, ao contrário da Liga das Nações, não estava sediada em um país "neutro", mas mantinha-se na capital do Estado mais poderoso do bloco, o que certamente despertava receios entre os latino-americanos.

No dia da cerimônia de abertura da VII Conferência Pan-Americana, 07 de dezembro de 1933, Acción circulou entre os leitores do Uruguai com uma crítica rotunda ao pan-americanismo. Dentre os diversos textos e manifestos publicados, abria aquele número um artigo, em que Quijano (1933c) argumentava que a Casa Branca se constituía em uma "fachada", ao passo que Wall Street representava o "real governo".

No que toca ao diagnóstico a respeito do "fracasso" do pan-americanismo até aquele momento, Antuña (1933, p. 8-10), embora acreditasse que seria possível insuflar-lhe novos alentos e transformá-lo em uma "Sociedade das Nações do Novo Mundo", coincidia parcialmente com Quijano e assinalava, em seu discurso de abertura, que era necessário arquitetar com urgência um "tribunal permanente e eficaz de justiça e conciliação".

Certamente, aquela conferência de Montevidéu sinalizava novos caminhos a serem seguidos no âmbito das relações exteriores entre os países americanos, acima de tudo, devido à eleição de Franklin D. Roosevelt como presidente dos Estados Unidos, bem como face ao crescente avanço das ideias nazifascistas na Europa e nas Américas.

Revista Eletrônica da ANPHLAC, ISSN 1679-1061, n.15, p. 198-224, jul./dez. 2013. http://revista.anphlac.org.br/ 
A ascensão de Roosevelt à presidência norte-americana, o New Deal e a Política da Boa Vizinhança transformaram notoriamente o debate a respeito das relações entre os Estados Unidos e a América Latina, mas não foi capaz de abolir completamente as reservas de Quijano e demais intelectuais nucleados em Acción e Marcha.

Ao longo da difícil edificação da Política da Boa Vizinhança, Quijano (1945, p.1) não deixou de apontar para suas fissuras, ao mesmo tempo em que realçou que as nações latino-americanas deveriam ser mais cautelosas ao estabelecer qualquer tipo de acordo com o vizinho anglo-saxão, pois o governo "conjuntural" de Roosevelt não duraria para sempre e já se encontrava em pugna contra os republicanos e alguns setores do Partido Democrata.

Por outro lado, Frugoni (1944, p. 90), no clima de batalha contra o nazifascismo, elogiou a aproximação entre o governo norte-americano e o britânico, criticou os setores favoráveis ao isolamento norte-americano e traçou um paralelo entre Woodrow Wilson e Franklin Roosevelt, destacando que esse havia conseguido extirpar "do panamericanismo oficial a noção antipática da política do garrote policial, preconizada pelo outro Roosevelt, substituindo-a pelo conceito decoroso de uma honorável política do bom vizinho".

Além disso, ao proferir um discurso em homenagem à entrada dos Estados Unidos na guerra, Frugoni (1944, p. 93-99) citou um fragmento de seu relato de viagem, publicado em 1918, e concluiu que Roosevelt e Walt Whitman representavam os dois principais símbolos coetâneos da luta pela democracia naquele país, deixando entrever que uma aliança com os britânicos poderia representar um canal bastante permeável para a disseminação das ideias do Partido Trabalhista entre os norte-americanos.

A publicação desses textos, enunciados originalmente em Montevidéu, pela editora argentina Claridad, não foi casual, uma vez que seus diretores e leitores estavam dispostos a escutar tais considerações, que também convergiam com a posição do aprismo peruano naquele momento.

Eis o momento ideal para Antuña (1941, p. 30) apresentar, em outubro de 1941, no Senado uruguaio, uma proposta de alinhamento do país com os Estados Unidos, empregando a revisão do líder aprista Haya de la Torre, que passava a preconizar a 
união "indo-americana" como única saída possível para a derrota nazifascista nas Américas ${ }^{6}$.

Em suma, Frugoni, Antuña e Quijano dedicaram especial atenção para as relações entre os Estados Unidos e a América Latina, desde ângulos distintos, embora seja possível observar alguns interessantes paralelos em determinados tópicos e períodos, contribuindo para uma mais ampla discussão sobre os constantes encontros e desencontros que caracterizaram tais contatos.

Antuña não construiu seu pensamento em torno da ideia de América Latina, uma vez que normalmente não falava nem em termos de América hispânica, mas de espanhola, o que não deixava dúvidas sobre sua visão tradicionalista a respeito da hispanidade. Frugoni hesitava em utilizar o termo e tampouco realizou amplas revisões sobre a necessidade de tal operação. Já Quijano foi um dos principais responsáveis por sua difusão nos círculos intelectuais e políticos do país e criticou tanto o seu suposto isolamento em relação ao restante do continente, desde muito cedo. Entretanto, não conseguiu fugir completamente de visões negativas sobre a formação dos países latinoamericanos.

Ainda durante o desenrolar da Segunda Guerra Mundial, ocorreu uma crescente aproximação entre o Uruguai e os Estados Unidos, marcada pela decisão do país sulamericano em lutar pelas fileiras aliadas, bem como com o Brasil, que se tornaram os dois países mais estratégicos para a defesa aliada no Atlântico Sul, face à frequente recusa argentina em estreitar os laços com os norte-americanos, o que levou inclusive à sua saída temporária da União Pan-Americana, em 1945, como anotou e aprovou Quijano (1945, p.1).

Pouco depois do ataque japonês às possessões ultramarinas norte-americanas, Antuña (1941, p. 5) propôs no Senado que o Uruguai abandonasse sua posição neutral e, ao citar Rui Barbosa, por meio das palavras de Afrânio de Mello Franco (1936) pronunciadas em uma conferência em Buenos Aires, afirmou que "entre a civilização e a barbárie não [podia] haver neutralidade". O senador colorado canalizava, dessa maneira, a voz de significativos setores da sociedade uruguaia, que apoiavam a

\footnotetext{
${ }^{6}$ Sobre o novo posicionamento de Haya de la Torre, cabe assinalar que, pouco mais de um ano após o discurso do senador Antuña, Marcha (1943, p. 11) publicou uma carta pública do intelectual peruano dirigida ao diplomata, político e jurista norte-americano Wendell Wilkie, e advertia os leitores que embora the propiciasse tal espaço para explicar melhor sua mudança de atitude, não a endossava completamente.
}

Revista Eletrônica da ANPHLAC, ISSN 1679-1061, n.15, p. 198-224, jul./dez. 2013. http://revista.anphlac.org.br/ 
consolidação da aliança com os Estados Unidos e a declaração de guerra aos países do Eixo, ao mesmo tempo em que amadureciam os movimentos antifascistas nacionais, em contato permanente com seus vizinhos argentinos.

Anteriormente ao discurso de Antuña, pronunciado em 09 de dezembro de 1941, os Estados Unidos já arquitetavam tal aproximação com o Uruguai, uma vez que concertara com o país sul-americano a elevação de suas legações diplomáticas à categoria de embaixadas, assim como também ocorreu entre o Uruguai e o México naquele mesmo ano.

Assim, o país platino aprimorava sua diplomacia e buscava o apoio de outras nações americanas, ao consolidar os habituais vínculos de aliança. Particularmente em relação aos Estados Unidos, como assinalou Juan Oddone (2004), a partir de então, se edificou uma corrente fluida de missões militares, comerciais e culturais nas duas direções, até princípios da década seguinte, quando a política de distensão argentina com os norte-americanos eclipsou, em certa medida, a posição estratégica uruguaia, que, segundo a fórmula do próprio embaixador norte-americano no Uruguai, Ellis Briggis, havia sido "um bom amigo de estação" (ODDONE, 2004, p. 66).

Se, de um lado, Antuña apoiou o estreitamento de laços entre o Uruguai e os EUA, bem como a contratação de um novo empréstimo com aquele país, acordado pelo ministro das relações exteriores Alberto Guani, em 1943, Quijano, de outro, reafirmava suas críticas a essa aproximação e advertia frequentemente a seus leitores que o Uruguai corria o risco de se transformar no "Gibraltar do Rio da Prata".

Diante disso, Quijano (1944) novamente não via outra saída para o Uruguai que renovar as diretrizes de sua política internacional e formar um bloco regional latinoamericano, se bem que sua visão vinha marcada por uma determinada dose de distopia, como podemos captar no seguinte fragmento:

Não negamos a possibilidade e também a necessidade de [edificar] grandes confederações econômicas de povos. Não acreditamos na confederação americana. $\mathrm{O}$ continente é um mito: um mito econômico, um mito geográfico e, além disso, um mito histórico.

$[\ldots]$

Nosso destino, sem perder de vista aquele equilíbrio do Rio da Prata, ao qual antes nos referimos, seria, assim, o de integrar uma grande conferência econômica regional, conservando nossa independência política. O federalismo artiguista [estaria], substancialmente, limitado ao campo econômico, porque cem anos de vida própria não se aventam em um dia, e porque é a única forma viável de promover o desaparecimento da dualidade em que nos debatemos desde as origens: personalidade definida e zelosa,

Revista Eletrônica da ANPHLAC, ISSN 1679-1061, n.15, p. 198-224, jul./dez. 2013. http://revista.anphlac.org.br/ 
dentro de uma comunidade histórica e geográfica que é também econômica. Este é o verdadeiro norte de nossa bússola. (p. 4-5)

A profissão de fé de Quijano sobre a posição que o Uruguai deveria ocupar ficava bem clara: era preciso se unir aos demais países latino-americanos, não de forma submissa e petiza, mas ancorado em uma defesa da personalidade nacional que integrasse o espaço histórico, geográfico e cultural latino-americano. Em face do avanço do pan-americanismo, que havia recebido um impulso significativo com o ataque dos japoneses aos Estados Unidos, Quijano pedia cautela e um olhar em perspectiva. O diagnóstico era pessimista: de um lado, os Estados Unidos do Norte. De outro, os "Estados Desunidos do Sul”, como afirmou inúmeras vezes.

\section{Considerações finais}

O presente artigo procurou traçar uma breve reflexão a respeito das divergências e alguns pontos em comum entre os três autores. Frugoni, Quijano e Antuña entrecruzaram seus olhares sobre a América Latina e os Estados Unidos em diversos momentos. Ao pensar sobre o lugar do Uruguai no concerto latino-americano e internacional, os três intelectuais enfocaram as relações conflituosas ou dialógicas entre os países das Américas.

A análise comparativa de seus textos permitiu-nos observar as suas principais inquietações a respeito do lugar do Uruguai na América. Suas respostas devem ser estreitamente articuladas ao contexto nacional e, principalmente Quijano e Frugoni, perceberam que o porvir do Uruguai deveria ser traçado no debate em conjunto com os outros países latino-americanos, em especial, com seus vizinhos mais próximos.

As obras escritas pelos autores foram marcadas pela diversidade de ideias e por determinada "ambiguidade" em distintos momentos. A ideia de América Latina oscilou entre um passado e um presente, repleto de dificuldades e injustiças, e um horizonte de transformação, acima de tudo, quando nos referimos a Frugoni e a Quijano.

A despeito disso, é possível delimitar uma orientação convergente entre as interpretações de Frugoni e Quijano, principalmente a partir de meados dos anos 1930. Esses autores foram críticos do hispanismo tradicional e conservador e buscaram promover a transformação da sociedade uruguaia por meio da palavra impressa e oral.

Para Frugoni e Quijano, os países latino-americanos apresentavam um potencial ainda pouco explorado para a construção de novas configurações políticas, devido ao

Revista Eletrônica da ANPHLAC, ISSN 1679-1061, n.15, p. 198-224, jul./dez. 2013. http://revista.anphlac.org.br/ 
cruzamento de povos e de culturas que os constituíam. Seus olhares buscaram perceber as diferenças entre as regiões da América Latina e não preconizaram fórmulas comuns para todos os seus Estados. Entretanto, não endossaram o difundido imaginário coletivo que sublinhava a "excepcionalidade" uruguaia no contexto regional.

Eles inscreveram a realidade uruguaia no horizonte latino-americano e, ainda que habitualmente destacassem as vicissitudes por que passavam os seus países, propuseram novos caminhos a seguir para a defesa e consolidação da democracia. Além disso, para os dois intelectuais, parte das incertezas e dos problemas que acometiam a América Latina nascia da convergência dos interesses das oligarquias internas e dos grupos dirigentes norte-americanos, que fomentavam grupos políticos que defendessem seus interesses.

Antuña, por outro lado, defendeu o hispanismo conservador, mas não rechaçou o pan-americanismo. Nesse sentido, foi um autor bastante singular e, em diversos momentos, teve que lidar com suas "contradições internas", pois não foi muito simples defender a tradição hispânica "católica" e "conservadora" simultaneamente à preconização da aliança com os Estados Unidos. No entanto, a presença, ao mesmo tempo, de hispanismo e pan-americanismo pode ser explicada pelo seu conservadorismo (no campo cultural e religioso), de um lado, e seu pragmatismo, de outro, no sentido de entrever, na aliança com os Estados Unidos, uma maneira inevitável de evitar ser esquecido pelo mundo. Isto é, via no país setentrional a base de construção do mundo moderno, até porque uma grande parte dos financiamentos para a indústria frigorífica e dos governos uruguaios provinha dos Estados Unidos. E, claro, da consciência, para os uruguaios, de que o país tinha que se integrar para crescer.

Também é interessante observar que, nem sempre, os intelectuais sustentam a "coerência" que esperamos deles. Muitas vezes, em nome das mais diversas questões e ou interesses, defendem ideias, muitas vezes "díspares" ou "incoerentes".

Antuña enfatizou os sinais negativos da América hispânica e propôs que os seus países constituintes deveriam nutrir-se dos exemplos anglo-saxões. Além disso, ele não deixou de propor um lugar intermediário para o Brasil, e, em alguns momentos, para o Chile e a Argentina, no cenário latino-americano, entre os "prósperos" Estados Unidos e a “instável” América hispânica.

Os três autores falaram, ainda que por caminhos distintos, sobre a necessidade da aproximação com outros países latino-americanos: Antuña, com o Brasil e a 
Argentina; Frugoni e Quijano, entre os setores trabalhadores, intelectuais e políticos reformistas de todos os países. Para Frugoni, os movimentos anti-imperialistas latinoamericanos necessitavam conquistar o apoio dos grupos trabalhadores norte-americanos e ampliar suas frentes de batalha, sob o risco de não serem ouvidos francamente ou derrotados.

A Revolução Mexicana e o período pós-revolucionário receberam especial atenção durante a década de 1920. Frugoni e Quijano apoiaram as suas principais reivindicações transformadoras e interpretaram o México como um bom exemplo para os países latino-americanos, se bem que sublinhassem que o contexto do Uruguai era distinto e que aquele movimento deveria ser filtrado em terras rioplatenses. Antuña, por outro lado, criticou os propósitos de secularização, tanto da Constituição Mexicana de 1917, quanto dos governos pós-revolucionários, e pediu a intervenção da Liga das Nações naquele país.

Durante os anos 1930 e 40, as trajetórias de Frugoni e Quijano convergiram em torno da oposição comum ao terrismo e demais governos ditatoriais latino-americanos. Antuña, por outro lado, atuou como um dos principais líderes intelectuais da esfera oficial e buscou fortalecer tanto a política externa pan-americanista do Uruguai, quanto a aproximação com os representantes intelectuais de outros regimes autoritários da América Latina.

Com o passar das décadas, principalmente durante os anos 1960 e 90, os discursos de Frugoni e Quijano obtiveram ampla recepção por parte de importantes intelectuais uruguaios, ao passo que Antuña passou por um processo gradativo de esquecimento, o que se fortaleceu com a construção de novas identidades uruguaias, permeadas pela crítica da ideia da "excepcionalidade" uruguaia no cenário latinoamericano.

\section{Fontes e Referências bibliográficas}

ANTUÑA, José. Ante la VII Conferencia I. Americana. Montevideo: J. Florensa, 1933. Defensa nacional y defensa continental. Montevideo: Comité Ejecutivo Nacional del Partido Colorado, 1941.

Penales, 1937.

El inquieto horizonte. Montevideo: Talleres Gráficos Institutos

El nuevo acento. Montevideo; Buenos Aires: Sociedad Amigos del Libro Rioplatense, 1935.

Revista Eletrônica da ANPHLAC, ISSN 1679-1061, n.15, p. 198-224, jul./dez. 2013.

http://revista.anphlac.org.br/ 
La verdad de América. In. Palabra. Conferencias y discursos: 19151927. Paris: Editorial Paris-América, 1927. p. 81-89.

L'Uruguay, le panaméricanisme et la Société des Nations. Paris: Imprimière Michel, 1929.

Panamericanismo. In. Acción parlamentaria. Montevideo: Gómez y Cia, 1924. p. 91-95.

Perspectivas de América. Temas, acontecimientos y monografías continentales. Buenos Aires: M. Gleizer, 1938.

ARDAO, Arturo. El latinoamericanismo de Quijano. In: MACHIN, Horacio; MORAÑA, Mabel (Eds.). Marcha y América Latina. Pittsburgh: Instituto Internacional de Literatura Iberoamericana/Universidad de Pittsburgh, 2003. p. 167-184.

República, 1987.

La inteligencia latinoamericana. Montevideo: Universidad de la

Oriental, 1986a.

Nuestra América Latina. Montevideo: Ediciones de la Banda

Panamericanismo y latinoamericanismo In. ZEA, Leopoldo (Coord.). América Latina en sus ideas. México: Siglo XXI; UNESCO, 1986b. p. 157-171.

BARRÁN, José Pedro, NAHUM, Benjamin. Battle, los estancieros y el Imperio Británico. Montevideo: Ediciones de la Banda Oriental, 1979-1987. 8 Tomos.

BRUIT, Héctor H. A invenção da América Latina. In: Revista Mestrado História, v. 5, p. 75-94, 2003.

CAETANO, Gerardo. Identidad nacional e imaginario colectivo en Uruguay. La síntesis perdurable del centenario. In: ACHUGAR, Hugo; CAETANO, Gerardo (Comps.). Identidad uruguaya: ¿mito, crisis o afirmación? 3 ed. Montevideo: Trilce, 1993. p. 7596.

. La república batllista. Ciudadanía, republicanismo y liberalismo en Uruguay (1910-1933). Montevidéu: Ediciones de la Banda Oriental, 2011.

; JACOB, Raúl. El nacimiento del terrismo (1930-1933). Montevidéu:

Ediciones de la Banda Oriental, 1989.

; RILLA José. El joven Quijano (1900-1933). Izquierda nacional y conciencia crítica. Montevideo: EBO, 1986.

CAPDEVILLA, Arturo. América: nuestras naciones ante los Estados Unidos. Buenos Aires: M. Gleizer, 1926.

CAPELATO, Maria Helena Rolim. América Latina: integração e história comparada. In: GEBRAN, Philomena; LEMOS, Maria Teresa T. B (Orgs.). América Latina: cultura, estado e sociedade. Rio de Janeiro: ANPHLAC, 1994. p. 83-108.

COLOMBI, Beatriz. Viaje intelectual, migraciones y desplazamientos en América Latina (1880-1915). Rosario: Beatriz Viterbo Editora, 2004.

DIARIO DE SESIONES DE LA CÁMARA DE REPRESENTANTES, Tomo 361. Montevideo: Imprenta Nacional, 1931.

Revista Eletrônica da ANPHLAC, ISSN 1679-1061, n.15, p. 198-224, jul./dez. 2013.

http://revista.anphlac.org.br/ 
DULCI, Tereza Maria Spyer. As Conferências Pan-Americanas: identidades, união aduaneira e arbitragem (1889 a 1928). São Paulo, 2008. Dissertação. (Mestrado em História) - Programa de Pós-Graduação em História Social, USP. São Paulo, 2008.

FRUGONI, Emilio. El laborismo británico. Sinopsis histórica e interpretativa. Montevideo: Editorial Afirmación, 1941.

. El socialismo en Estados Unidos. In: Génesis, esencia y fundamentos del socialismo. Buenos Aires: Américalee, 1947. Tomo II. p. 211-244.

1918.

. En la otra América. In: Nosotros, a. 12, v. 28, n. 107, p. 332-349, mar.

La India y el laborismo inglés. Ariel. In: Revista del Centro de Estudiantes Ariel, n. 39, p. 4-6, mai. 1930.

La lección de Méjico. Montevideo: Tip. Augusta, 1928.

Aires: Claridad, s/d.

La revolución del machete. Panorama político del Uruguay. Buenos

Las tres dimensiones de la democracia. Buenos Aires: Claridad, 1944.

FUNES, Patricia. Del Mundus Novus al novomundismo. Algunas reflexiones sobre el nombre de América Latina. In: DAYREL, Eliane Garcindo; IOKOI, Zilda M. Gricoli (Coords.). América Latina contemporânea: desafios e perspectivas. Rio de Janeiro: Expressão e Cultura; São Paulo: Edusp, 1996. p. 77-95.

Salvar la nación: Buenos intelectuales, cultura y política en los años veinte latinoamericanos. Aires: Prometeo, 2006.

GONZÁLEZ, Alexandra Pita, RAMÍREZ, Rogelio Ventura. La Convención sobre la enseñanza de la Historia: educar para la comprensión americana. Disponível em: <Http://www.caei.com.ar/es/programas/historia/18.pdf>. Acesso em: 09/12/2007.

JACOB, Raúl. El Uruguay de Terra, 1931-1938. Montevideo: Ediciones de la Banda Oriental, 1983.

JUNQUEIRA, Mary A. Ciência, técnica e as expedições da marinha de guerra norteamericana, U. S. Navy, em direção à América Latina. In: Varia História, v. 23, n. 38, p. 334-349, jul.-dez. 2007.

MARCHA. Tópicos de América. V. H. de la Torre. Carta abierta de Haya de la Torre, líder del Aprismo, a Wendell Wilkie. In: Marcha, a. IV, n. 169, p. 11, 22 jan. 1943.

ODDONE, Juan. Vecinos en discordia. Argentina, Uruguay y la política hemisférica de los Estados Unidos. Selección de documentos, 1945-1955. 2 ed. Montevideo: Ediciones El Galeón; Universidad de la República, 2004.

QUIJANO, Carlos. Conclusiones sobre nuestra política internacional. Estados Desunidos del Sur y Estados Unidos del Norte. Las directivas fundamentales de una política internacional. In: Marcha, a. VI, n. 240, p. 4-5, 07 jul. 1944.

El Sanhedrín de Chapultepec empieza condenando al justo. In: Marcha, a. IV, n. 272, p.1, 02 mar. 1945.

dez. 1933c.

. Estados Unidos y los banqueros. In: Acción, a. II, n. 64, p. 1; 5, 07

Franklin Roosevelt. In: Marcha, a. VI, n. 278, p. 1, 20 abr. 1945.

Revista Eletrônica da ANPHLAC, ISSN 1679-1061, n.15, p. 198-224, jul./dez. 2013.

http://revista.anphlac.org.br/ 
QUIJANO, Carlos. La cabeza en el tajo. In: Marcha, a. VI, n. 282, p. 4-5, 18 mai. 1945.

La doctrina de Monroe en el pacto de la Sociedad de Naciones. In:

Acción, a. I, n. 21, p. 5-6, 22 ago. 1933a.

Las Conferencias Panamericanas. Santiago y La Habana. In: Acción, a. I, n. 23, p. 8, 05 set. 1932.

Las directivas fundamentales de una política internacional. In: Marcha, a. VI, n. 240, p. 5, 07 jul. 1944.

. Nicaragua. Ensayo sobre el imperialismo de los Estados Unidos. Paris: Agencia Mundial de Librería, 1928.

Otra Conferencia Panamericana. In: Acción, a. II, n. 61, p. 1, 11 nov. $1933 b$.

TERÁN, Oscar. El primer antiimperialismo latinoamericano. In: Punto de vista, a. IV, n. 12, p. 3-10, 1981.

ZANETTI, Susana. Modernidad y religación: una perspectiva continental (1880-1916). In: PIZARRO, Ana (Org.). América Latina: palavra, literatura e cultura. São Paulo: Memorial; Campinas: Unicamp, 1994. V. 2. p. 489-534.

ZUBILLAGA, Carlos. Breve panorama da imigração maciça no Uruguai (1870-1931). In: FAUSTO, Boris (Org.). Fazer a América. São Paulo: EDUSP, 1999. p. 419-460.

Revista Eletrônica da ANPHLAC, ISSN 1679-1061, n.15, p. 198-224, jul./dez. 2013. http://revista.anphlac.org.br/ 